\title{
CHARACTERIZATION OF INTERACTION BETWEEN BUDDLEOSIDE AND BOVINE SERUM ALBUMIN
}

Shan Sun ${ }^{\mathrm{a}}$, Zhe Yuan ${ }^{\mathrm{a}}$ and Yuanqi $\mathrm{Lu}^{\mathrm{a}, *, \mathbb{1}}$

${ }^{a}$ Analysis and Testing Centre, Dezhou University, Dezhou 253011, Shandong Province, P. R. China

Recebido em 07/01/2020; aceito em 15/04/2020; publicado na web em 15/06/2020

\begin{abstract}
The primary objective of this study was to investigate the binding of buddleoside to bovine serum albumin (BSA) by different analytical techniques. The analytical principles of affinity capillary electrophoresis (ACE) and fluorescence spectroscopy used in the experiments were different. Mobility (M) that is independent of viscosity of the operating buffer and voltage was chosen to eliminate the effects of electroosmotic flow (EOF) in $\mathrm{ACE}$ and was applied to estimate the binding constant Ka. The quenching constant $\mathrm{K}_{\mathrm{sv}}$, binding site number $\mathrm{n}$ and binding constant $\mathrm{Kb}$ were provided by the fluorescence quenching method. After data analysis of the fluorescence quenching process, it can be seen that the quenching of BSA by buddleoside is a static quenching method. The binding constants between buddleoside and BSA obtained from ACE and fluorescence spectra were $1.218 \times 10^{5}$ and $1.1915 \times 10^{5}$, respectively. According to the thermodynamic parameters of $\Delta \mathrm{G}, \Delta \mathrm{H}$ and $\Delta \mathrm{S}$, it can be inferred that Van Der Waals force and hydrogen bonding force exist in the interaction between buddleoside and BSA. This study can provide a reference for the study of the transport and function mechanism of buddleoside in vivo.
\end{abstract}

Keywords: buddleoside; bovine serum albumin (BSA); affinity capillary electrophoresis (ACE); fluorescence spectroscopy; binding constants.

\section{INTRODUCTION}

After entering the blood circulatory system, drugs will be stored and transported by plasma to reach the target tissue and exert efficacy. ${ }^{1}$ Serum albumin is the most abundant carrier protein in plasma and the major soluble protein constituents of the blood circulation. ${ }^{2}$ So, the mechanism studying of the interaction between drugs and serum albumin is helpful to understand the transportation and distribution of drugs in vivo on the molecular level. Human serum albumin (HSA) usually play an important role in the pharmacokinetics and toxicokinetics. ${ }^{3}$ It has been reported that HSA can interact reversibly with a variety of exogenous and endogenous substances, including drugs. ${ }^{4}$ Bovine serum albumin (BSA) is composed of 583 amino acid residues. It has three domains: domain I, II, and III. Each domain has two subdomains, A and B. The two main drug-binding sites (site I and site II) are located in the subdomain IIA and the subdomain IIIA, respectively. ${ }^{5-7}$ BSA is one of the most widely studied proteins because of its structural homology with HSA. ${ }^{8-11}$

Buddleoside is a major biological active substance derived from the traditional Chinese herbal medicine called Chrysanthemum indicum. ${ }^{12,13}$ The structure of buddleoside is shown in Figure 1. Buddleoside is a kind of flavonoids in Chrysanthemum indicum, with anti-inflammatory, analgesic, sweating, lowering blood pressure, antistress, anxiety, antipyretic and so on. ${ }^{14-16}$ At present, there are many studies on buddleoside, ${ }^{17,18}$ but no any research on the interaction between buddleoside and serum albumin.

In this paper, affinity capillary electrophoresis (ACE) and fluorescence spectroscopy were used to study the spectral characteristics about the binding interaction between buddleoside and BSA in detail. The data of the study showed that the binding constants and the binding sites numbers obtained by the two analytical methods were very similar. The results can provide theoretical support for the research of medicinal mechanism of buddleoside.

*e-mail: yuanqilu@ 126.com<smiles>COc1ccc(-c2cc(=O)c3c(O)cc(OC4OC(COC5OC(C)C(O)C(O)C5O)C(O)C(O)C4O)cc3o2)cc1</smiles>

Figure 1. The molecular structure of buddleoside

\section{EXPERIMENTAL PART}

\section{Instrument}

The ACE experiment was performed on a Beckman P/ACE MDQ system with a photodiode array detector. Data collection and analysis was done with Beckman 32 Karat software (version 7.0). An uncoated fused silica capillary (Yongnian reafine chromatograph, China) of $64.5 \mathrm{~cm}$ (54 cm of effective length) x $75 \mu \mathrm{m}$ (i.d.) was used. The fluorescence spectroscopy experiments were performed by using the F-4600 type Fluorescence Spectrophotometer (Hitachi High-Technologies Co., Ltd., Tokyo, Japan). During the experiment, PHSJ-4A measuring instrument (Shanghai Precision \& Scientific Instrument Co., Shanghai, China) was applied to determine different $\mathrm{pH}$.

\section{Chemicals and solutions}

Buddleoside and BSA were purchased from Shanghai Yuanye Biotechnology Company (Shanghai, China) and Shanghai Aladdin 
Biotechnology Co., Ltd. (Shanghai, China), respectively. Both borax and boric acid were bought from Sigma (St. Louis, Missouri, USA). The other reagents used in the experiments were of analytical grade.

The $\mathrm{pH}$ of the borate buffer containing $30 \mathrm{mmol} \mathrm{L}^{-1}$ borax was adjusted to 8.8 with $100 \mathrm{mmol} \mathrm{L}^{-1}$ boric acid. The $1 \mathrm{mmol} \mathrm{L}-1$ buddleoside stock solution was prepared in DMSO and the $100 \mu \mathrm{mol} \mathrm{L}{ }^{-1}$ BSA stock solution was dissolved in $30 \mathrm{mmol} \mathrm{L}^{-1}$ borate buffer. During the ACE, the sample solution was diluted to $100 \mu \mathrm{mol} \mathrm{L} \mathrm{L}^{-1}$ with borate buffer solution prior to each injection. DMSO was chosen to label EOF which is a cationic sheath formed on the inner wall of the capillary tube. EOF can drive the whole fluid in the capillary tube to the cathode. Experimental BSA solution $\left(0-10 \mu \mathrm{mol} \mathrm{L}^{-1}\right)$ was prepared by diluting BSA stock solution with borate buffer containing $0.05 \mathrm{~mol} \mathrm{~L}^{-1}$ glycine (Gly). During the fluorescence measurement, the $\mathrm{BSA}$ and $\mathrm{NaCl}$ concentrations were keeped at $2 \mu \mathrm{mol} \mathrm{L}{ }^{-1}$ and $0.1 \mathrm{~mol} \mathrm{~L}^{-1}$ in $30 \mathrm{mmol} \mathrm{L}^{-1}$ borax buffer solution ( $\mathrm{pH}=8.8)$, respectively. At the same time, the ratios of the concentration ratios of buddleoside to BSA were $0,3,5,7,8,9$ and 10 , respectively. All solutions needed to be filtered through $0.22 \mu \mathrm{m}$ filters and stored refrigerator at $4{ }^{\circ} \mathrm{C}$ before experiments.

\section{Procedures}

New capillaries were rinsed with $1 \mathrm{~mol} \mathrm{~L}^{-1} \mathrm{NaOH}$ for 5 min, washed with water for $10 \mathrm{~min}$ and conditioned with borax buffer for 15 min before use. To improve great peak shape and reproducibility, the capillary was rinsed sequentially for $3 \mathrm{~min}$ by $\mathrm{NaOH}$, water and buffer.

In the ACE analysis, analytes were detected at $334 \mathrm{~nm}$ and injected by applying a pressure of 0.5 psi for $5 \mathrm{~s}$. The operating voltage was set to $15 \mathrm{kV}$. The electrophoresis was performed with 30 mmol L-1 borate buffer ( $\mathrm{pH} 8.8,0.05 \mathrm{~mol} \mathrm{~L}^{-1} \mathrm{Gly}$ ) including different

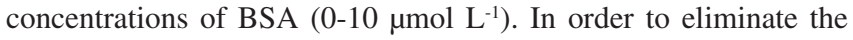
effect of BSA adsorption on the inner wall of the capillary, Gly, an amphotericion, was added to compete with BSA. Besides, the BSA concentration was low ( 0 to $\left.10 \mu \mathrm{mol} \mathrm{L}^{-1}\right)$ in this study. In fluorescence experiments, $2 \mu \mathrm{mol} \mathrm{L}{ }^{-1}$ BSA solution was titrated with different buddleoside concentrations $(0,6,10,14,16,18,20 \mu \mathrm{mol} \mathrm{L}-1)$. Fluorescence spectra were recorded at $298 \mathrm{~K}$ and the scanning wavelength range was $290-600 \mathrm{~nm}$. The excitation wavelength was set at $280 \mathrm{~nm}$. Emission and excitation slits were $10 \mathrm{~nm}$.

\section{RESULTS AND DISCUSSION}

\section{Theory of the estimation of binding constants by ACE method}

In the research of drug and protein interaction, drugs or the protein can be added into the ACE running buffer. In this experiment, considering the cost of the experiment, BSA was added to the buffer solution as an additive, and the drug concentration was used as a fixed amount. The drug and serum albumin are assumed to be a 1: 1 combination. The following equation represents the drug-serum albumin binding reaction. ${ }^{19,20}$

$$
\begin{gathered}
\mathrm{D}+\mathrm{P}=\mathrm{DP} \\
\mathrm{Ka}=[\mathrm{DP}] /[\mathrm{D}][\mathrm{P}]
\end{gathered}
$$

where $[\mathrm{D}],[\mathrm{P}],[\mathrm{DP}]$ represent the concentrations of the drug, serum albumin and drug-protein complex, respectively. Equation (2) is used to calculate $\mathrm{Ka}^{21}$

$$
\begin{gathered}
1 / \Delta \mu_{\mathrm{D}}^{\mathrm{P}}=\left[1 /\left(\mathrm{Ka} \times \Delta \mu_{\max }\right) \times 1 / \mathrm{c}(\mathrm{P})\right]+1 / \Delta \mu_{\max } \\
\Delta \mu_{\mathrm{D}}^{\mathrm{P}}=\mu_{\mathrm{D}}^{\mathrm{P}}-\mu_{\mathrm{D}}
\end{gathered}
$$

where $\mu_{D}^{P}$ and $\mu_{D}$ represents the electrophoretic mobility of drugs in the presence and absence of protein. $\Delta \mu_{\max }=\mu_{D P}-\mu_{D}$, where $\mu_{D P}$ is the mobility of the complex. Linear graphs were obtained by plotting $1 / \Delta \mu_{\mathrm{D}}^{\mathrm{P}}$ against $1 / \mathrm{c}(\mathrm{P})$. Therefore, the binding constant can be calculated from the intercept/slope. However, the analysis method has limitations due to the protein added to the buffer. Protein adsorption onto the capillary wall can cause problems in separation and loss of protein and drug. The buffer viscosity and EOF varies as the protein concentration changes and causes a difference in $\mathrm{Ka}^{22}$ In order to minimize this phenomenon, the mobility ratio (M) was introduced. ${ }^{23} \mathrm{M}$ has proven to be independent of operating voltage and buffer viscosity, so it can estimate Ka more accurately. The following formula shows the calculation of M. ${ }^{24}$

$$
\mathrm{M}=\left(\mu_{\mathrm{eo}}+\mu_{\mathrm{D}}^{\mathrm{P}}\right) / \mu_{\mathrm{eo}}=\mathrm{t}_{\mathrm{eo}} / \mathrm{t}_{\mathrm{D}}^{\mathrm{P}}+1
$$

where $t_{\mathrm{eo}}$ represents the migration time of the EOF and $t_{D}^{\mathrm{P}}$ represents the migration time of the analyte. Therefore, the Scatchard equation is corrected to the following equation (4). ${ }^{25}$

$$
\begin{gathered}
1 / \Delta \mathrm{M}_{\mathrm{D}}^{\mathrm{P}}=\left[1 /\left(\mathrm{Ka} \times \Delta \mathrm{M}_{\max }\right) \times 1 / \mathrm{c}(\mathrm{P})\right]+1 / \Delta \mathrm{M}_{\max } \\
\Delta \mathrm{M}_{\mathrm{D}}^{\mathrm{P}}=\mathrm{M}_{\mathrm{D}}^{\mathrm{P}}-\mathrm{M}_{\mathrm{D}}, \Delta \mathrm{M}_{\max }=\mathrm{M}_{\mathrm{DP}}-\mathrm{M}_{\mathrm{D}}
\end{gathered}
$$

where $\mathrm{M}_{\mathrm{D}}^{\mathrm{P}}$ and $\mathrm{M}_{\mathrm{D}}$ represent the mobility of the drug in the presence and absence of the protein, respectively. $\mathrm{M}_{\mathrm{DP}}$ represents the mobility of the complex. In this study, Scatchard analysis is carried out with equation 4 , and $\mathrm{Ka}$ is obtained by linear fitting.

\section{Measurement of the drug/BSA binding constant by ACE}

Peak time of buddleoside $\left(\mathrm{t}_{\mathrm{D}}^{\mathrm{P}}\right)$ and DMSO $\left(\mathrm{t}_{\mathrm{R}}\right)$ are listed in Table 1. At 298K, with the change of BSA concentration, the electrophoretograms of the complex formed by buddleoside and BSA is shown in Figure 2. From Table 1 and Figure 2, it can be seen that with the increase of BSA concentration, the peaks of buddleoside and DMSO shift to the right. Due to the complexation between buddleoside and BSA, the $\mathrm{m} / \mathrm{z}$ of the complex increases and the peak time of the complex is later than the uncomplexed form. With the increase of BSA concentration, the peak pattern of the buddleoside is gradually asymmetric. At different temperatures, the Scatchard equation and Ka calculated from the intercept and slope ratios of buddleoside and BSA are shown in Table 2 . The binding constant Ka decreased from $1.218 \times 10^{5}$ to $2.330 \times 10^{4}$ with the increase of temperature.

Table 1. Migration time of buddleoside obtained by ACE method and their transformation

\begin{tabular}{lccccc}
\hline & $\mathrm{t}_{\mathrm{R}}, \min$ & $\mathrm{t}_{\mathrm{D}}^{\mathrm{P}}, \min$ & $\Delta \mathrm{M}_{\mathrm{D}}^{\mathrm{P}}$ & $1 / \Delta \mathrm{M}_{\mathrm{D}}^{\mathrm{P}}$ & $\begin{array}{c}1 / \mathrm{c}(\mathrm{P}), \\
\left(\mu \mathrm{mol} \mathrm{L}^{-1}\right)\end{array}$ \\
\hline 0 & 4.986 & 5.179 & & & \\
2 & 5.415 & 5.654 & -0.0050 & -200.000 & 0.5000 \\
4 & 5.609 & 5.867 & -0.0067 & -149.254 & 0.2500 \\
6 & 5.756 & 6.042 & -0.0100 & -100.000 & 0.1667 \\
8 & 5.866 & 6.183 & -0.0140 & -71.429 & 0.1250 \\
10 & 6.003 & 6.339 & -0.0148 & -67.568 & 0.1000 \\
\hline
\end{tabular}

\section{Affinity measurements using fluorescence spectroscopy}

To further clarify the interaction between buddleoside and BSA, fluorescence quenching experiment was carried out. The binding 


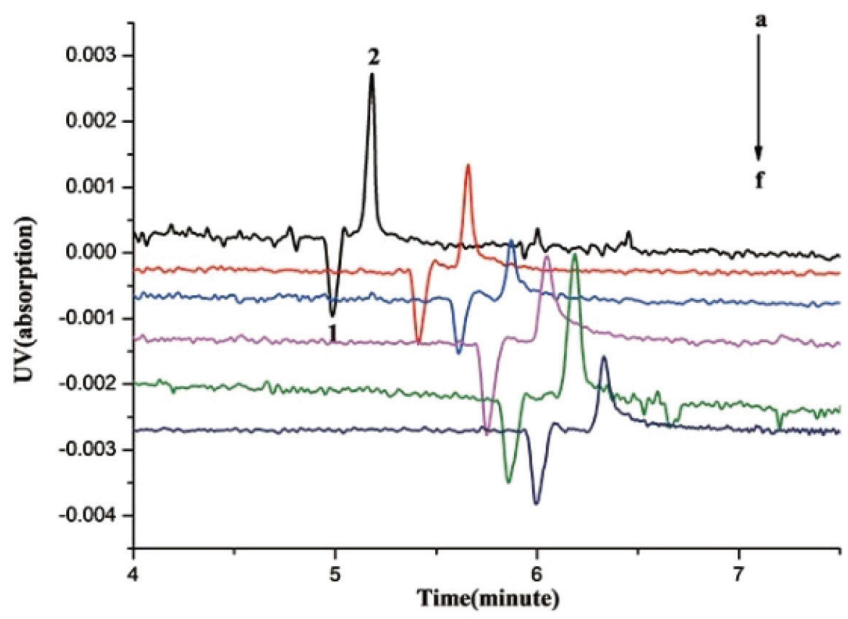

Figure 2. Electropherograms of buddleoside and BSA conjugate at different BSA concentrations in $30 \mathrm{mmol} \mathrm{L}^{-1}$ borate buffer $\left(\mathrm{pH}=8.8,0.05 \mathrm{~mol} \mathrm{~L}^{-1}\right.$ Gly). Among them, a-f represents the BSA concentration of 0, 2, 4, 6, 8, and $10 \mu \mathrm{mol} L^{-1}$, respectively, and the concentration of buddleoside is fixed at 100 umol L-1. Peak1: DMSO, 2: buddleoside

of buddleoside and BSA was realized by evaluating the intrinsic fluorescence intensity of BSA after adding different concentrations of buddleoside. The quenching effect of fluorescence can usually be categorized into dynamic quenching and static quenching. Dynamic quenching is the process of fluorescence weakening caused by collision between fluorescent group and quenching agent, while static quenching is the process of fluorescence weakening caused by the formation of complex of fluorophore and quencher. In order to explore the mechanism of fluorescence quenching of buddleoside to BSA, we firstly assume that it is a dynamic quenching process. According to Stern-Volmer equation (5), the regression curve is drawn. ${ }^{26}$

$$
\mathrm{F}_{0} / \mathrm{F}=1+\mathrm{K}_{\mathrm{Q}} \times \tau_{0} \times[\mathrm{Q}]=1+\mathrm{K}_{\mathrm{SV}} \times[\mathrm{Q}]
$$

In the above formula, $\mathrm{F}_{0}$ and $\mathrm{F}$ represent the fluorescence intensity of BSA before and after the addition of buddleoside, respectively. $\mathrm{K}_{\mathrm{Q}}$ and $\mathrm{K}_{\mathrm{SV}}$ represent the quenching rate constant and dynamic quenching constant, respectively, while $\tau_{0}$ and [Q] represent the average lifespan of biomolecules without a quencher $\left(\tau_{0}=10^{-8} \mathrm{~s}\right)^{27}$ and quencher concentration, respectively. The calculated $\mathrm{K}_{\mathrm{Q}}$ is $5.17 \times 10^{12}$, which is much larger than the maximum scattering collision quenching constant $\left(2.0 \times 10^{10} \mathrm{~L} \mathrm{~mol}^{-1} \mathrm{~s}^{-1}\right) .{ }^{28}$ It can be seen from the above data that the quenching of buddleoside on BSA should not be a dynamic quenching process, but a static quenching. The following formula (6) represents the calculation method of the binding constant in the static quenching form. ${ }^{29,30}$

$$
\log _{10}\left[\left(\mathrm{~F}_{0}-\mathrm{F}\right) / \mathrm{F}\right]=\log _{10}(\mathrm{~Kb})+\mathrm{n} \log _{10}[\mathrm{Q}]
$$

In the above formula, $\mathrm{Kb}$ is the binding constant of buddleoside and BSA, which can be determined by formula (6). And $\mathrm{n}$ is the number of binding sites of each BSA. $F_{0}, F$ and $Q$ in the formula have the same meaning as formula 5. The fluorescence spectrum of the interaction between the buddleoside and BSA is shown in Figure 3. The fluorescence intensity of BSA decreased with the increase of the concentration of buddleoside, which indicated that buddleoside could quench BSA obviously. The static quenching equation and linear regression are shown in Figure 4. The experimental results of static quenching (Table 3) are basically the same as the binding constant and number of binding sites of ACE. Because the sensitivity and detection principle of the two methods are different, it is acceptable that there are slight differences between them.

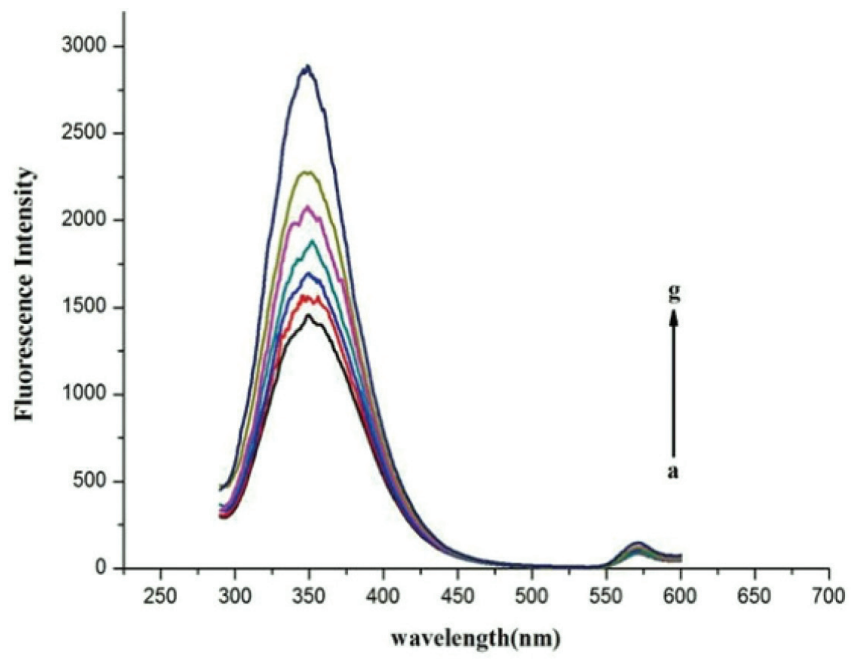

Figure 3. Fluorescence spectrum of buddleoside and BSA complex. The concentration of BSA was fixed at $2 \mu \mathrm{mol} L^{-1}$, and the concentration of buddleoside changed from 0 to $20 \mu \mathrm{mol} \mathrm{L} L^{-1}$ (a-g: 0, 6, 10, 14, 16, 18 and $20 \mu \mathrm{mol} L^{-1}$ )

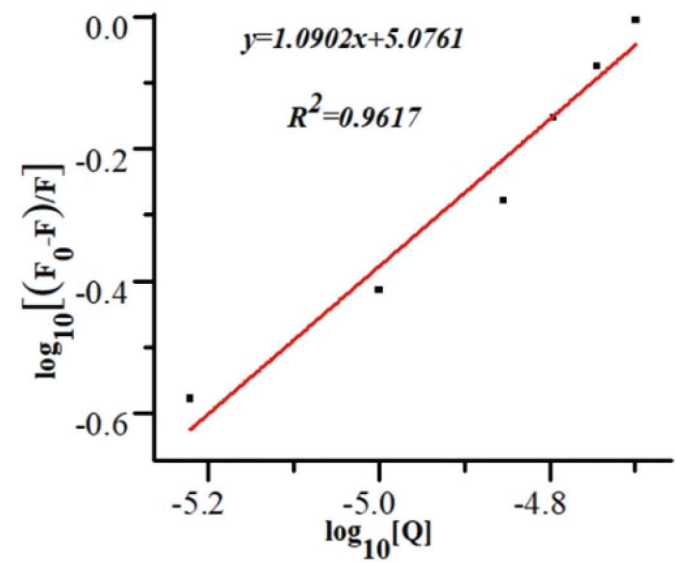

Figure 4. Stern-Volmer equation and linear regression diagram of static quenching

\section{Analysis of interaction forces by ACE method}

Generally speaking, four forces including hydrogen bond, Van Der Waals force, electrostatic interaction and hydrophobic interaction are the main interactions between small molecules and proteins. The thermodynamic parameters such as entropy change $(\Delta S)$, enthalpy

Table 2. The Ka and Scatchard equation of buddleoside-protein at different temperatures

\begin{tabular}{ccccc}
\hline & $\mathrm{T}$ & Scatchard equation & $\left.\mathrm{Ka},(\mathrm{L} \mathrm{mol})^{-1}\right)$ & $\mathrm{R}^{2}$ \\
\hline \multirow{3}{*}{ Buddleoside } & $298 \mathrm{~K}$ & $\mathrm{y}=-335.95 \mathrm{x}-40.94$ & $1.218 \times 10^{5}$ & 0.9324 \\
& $303 \mathrm{~K}$ & $\mathrm{y}=-475.46 \mathrm{x}-43.60$ & $9.100 \times 10^{4}$ & 0.9757 \\
\hline
\end{tabular}


Table 3. Stern-Volmer quenching constants and binding parameters for the interaction of BSA with buddleoside at $298 \mathrm{~K}$

\begin{tabular}{|c|c|c|c|c|c|c|}
\hline \multirow{2}{*}{$\mathrm{T}$} & \multicolumn{3}{|c|}{ Stern-Volmer quenching constants } & \multicolumn{3}{|c|}{ Binding parameters } \\
\hline & $\mathrm{K}_{\mathrm{SV}},\left(\mathrm{L} \mathrm{mol}^{-1}\right)$ & $\mathrm{K}_{\mathrm{Q}},\left(\mathrm{L} \mathrm{mol}^{-1} \cdot \mathrm{s}^{-1}\right)$ & $\mathrm{R}^{2}$ & $\mathrm{~Kb},\left(\mathrm{~L} \mathrm{~mol}^{-1}\right)$ & $\mathrm{n}$ & $\mathrm{R}^{2}$ \\
\hline $298 \mathrm{~K}$ & $5.17 \times 10^{4}$ & $5.17 \times 10^{12}$ & 0.9566 & $1.1915 \times 10^{5}$ & 1.0902 & 0.9617 \\
\hline
\end{tabular}

change $(\Delta \mathrm{H})$ and free energy change $(\Delta \mathrm{G})$ are of great significance for the determination of the binding mode of drugs and proteins. Equation 7,8 and 9 are applied to calculate the thermodynamic constants of the binding process of buddleoside and BSA: ${ }^{31}$

$$
\begin{gathered}
\ln \mathrm{Ka}=(-\Delta \mathrm{H} / \mathrm{RT})+\Delta \mathrm{S} / \mathrm{R} \\
\Delta \mathrm{G}=-\mathrm{RT} \ln \mathrm{K} \\
\Delta \mathrm{S}=(\Delta \mathrm{H}-\Delta \mathrm{G}) / \mathrm{T}
\end{gathered}
$$

where $\mathrm{R}$ and $\mathrm{Ka}$ are gas constants and binding constants at corresponding temperatures, respectively. In order to further elaborate the process of the combination of buddleoside and BSA, ACE method is used to study the thermodynamic parameters of the interaction process of buddleoside and BSA at 298, 303 and $308 \mathrm{~K}$ in this study. The data is shown in Table 4. The negative $\Delta \mathrm{G}$ indicates that the interaction between buddleoside and BSA is spontaneous. The negative $\Delta \mathrm{S}$ and $\Delta \mathrm{H}$ are often used as evidence of Van Der Waals force. ${ }^{32}$ In the exothermic process or in the presence of hydrogen bonds, the phenomenon of $\Delta \mathrm{H}$ less than zero can also be observed. When $\Delta \mathrm{S}$ is greater than zero, it is often considered to have hydrophobic effect. In aqueous solution, when $\Delta \mathrm{S}$ is greater than zero and $\Delta \mathrm{H}$ is less than zero (close to zero), it indicates the generation of electrostatic interaction. ${ }^{33}$

Table 4. Thermodynamic parameters of the buddleoside-protein binding process at different temperatures

\begin{tabular}{ccccc}
\hline & $\mathrm{T}$ & $\begin{array}{c}\triangle \mathrm{H}, \\
\left(\mathrm{kJ} \mathrm{L} \mathrm{mol}^{-1}\right)\end{array}$ & $\begin{array}{c}\triangle \mathrm{S}, \\
\left(\mathrm{kJ} \mathrm{L} \mathrm{mol}^{-1}\right)\end{array}$ & $\begin{array}{c}\triangle \mathrm{G}, \\
\left(\mathrm{kJ} \mathrm{L} \mathrm{mol}^{-1}\right)\end{array}$ \\
\hline \multirow{3}{*}{ Buddleoside } & $298 \mathrm{~K}$ & & -0.3246 & -29.0127 \\
& $303 \mathrm{~K}$ & -125.749 & -0.3201 & -28.7651 \\
& $308 \mathrm{~K}$ & & -0.3247 & -25.7511 \\
\hline
\end{tabular}

\section{CONCLUSIONS}

In the present work, the interaction between buddleoside and BSA was studied by ACE and fluorescence spectroscopy. The binding constant of fluorescence quenching of buddleoside and BSA is $1.1915 \times$ $10^{5}$, and the binding constant obtained by ACE is $1.218 \times 10^{5}$. The results of the two methods are basically the same. This shows that both methods have good applicability in the study of substance binding. At the same time, it can be seen that buddleoside has strong binding ability to BSA. From the fluorescence spectrum data, buddleoside quenches the endogenous fluorescence of BSA. And this is a static quenching process. The binding site $\mathrm{n}$ obtained in the study is about one, which is consistent with the experimental hypothesis. This indicates that there is only one binding site between buddleoside and BSA. The number of binding sites can provide reference for the study on the mechanism of transport of buddleoside by serum albumin in vivo. The thermodynamic parameters of the buddleoside and BSA obtained by the ACE method during the binding process indicate that Van Der Waals forces and hydrogen bonding play important roles. This research can provide theoretical guidance for the clinical application of buddleoside. The efficacy and metabolism of buddleoside in the human body will be further studied in future studies.

\section{ACKNOWLEDGEMENT}

We are very grateful for the support of Natural Science Foundation of Shandong Province (Grant No. ZR2018LB021) for our work.

\section{REFERENCES}

1. Raza, M.; Ahmad, A.; Yue, F.; Khan, Z.; Jiang, Y.; Wei, Y.; Raza, S.; He, W. W.; Khan, F.; Qipeng, Y.; J. Photochem. Photobiol. B. 2017, 170,6 .

2. Poór, M.; Kunsági-Máté, S.; Bálint, M.; Hetényi, C.; Gerner, Z.; Lemli, B.; J. Photochem. Photobiol. B. 2017, 170, 16.

3. Ma, L.; Maragos, C. M.; Y. H.; Mycotoxin Res. 2018, 34, 39.

4. Zhang, Y. L.; Sha, Y. J.; Qian, K.; Chen, X.; Chen, Q.; Electrophoresis 2017, 38, 1038 .

5. Nunes, N. M.; Pacheco, A. F. C.; Agudelo, Á. J. P.; da Silva, L. H. M.; Pinto, M. S.; Hespanhol, M. C.; Pires, A. C. S.; Food Chem. 2017, 237, 525.

6. Manjushree, M.; Revanasiddappa Hosakere, D.; J. Mol. Liq. 2017, 237, 23.

7. Minic, S.; Stanic-Vucinic, D.; Radomirovic, M.; Radibratovic, M.; Milcic, M.; Nikolic, M.; Cirkovic-Velickovic, T.; Food Chem. 2018, 239, 1090.

8. Lou, Y. Y.; Zhou, K. L.; Pan, D. Q.; Shen, J. L.; Shi, J. H.; J. Photochem. Photobiol. B 2017, 167, 158.

9. Gałęcki, K.; Despotović, B.; Galloway, C.; Ioannidis, A. G.; Janani, T.; Nakamura, Y.; Oluyinka, G.; Biotechnol. Food Sci. 2012, 76, 3.

10. Swarup, R.; Raj Kumar, N.; Sintu, G.; Majumdar, K. C.; Tapan, K. D.; J. Pharm. Anal. 2017, 7, 19.

11. Domínguez, M.; Cortes-Figueroa, J. E.; Melendez, E.; J. Chem. Educ. 2018, 95, 152.

12. He, D.; Ru, X.; Wen, L.; Wen, Y.; Jiang, H.; Bruce, I. C.; Jin, J.; Ma, X.; Xia, Q.; J. Ethnopharmacol. 2012, 139, 68.

13. Chen, H. Y.; Ni, J.; Zhang, H.; Chin. J. Exp. Tradit. Med. Formulae 2013, 19, 122.

14. Martínez-Vázquez, M.; Ramírez Apan, T. O.; Lastra, A. L.; Bye, R.; Planta Med. 1998, 64, 134.

15. Yang, Y.; Chen, B.; Liang, K. L.; Su, J.; Chen, S. H.; Lv, G. Y.; China J. Chin. Mater. Med. 2017, 42, 1370.

16. Han, Y. C.; Gong, H. Y.; Liu, W.; Chen, N.; Cui, Y. X.; Wu, M. X.; Wang, L. G.; Rui, F. S.; Chin. J. Exp. Tradit. Med. Formulae 2013, 19, 88.

17. Huang, Y.; Feng, Y.; Tang, G. Y.; Li, M. Y.; Zhang, T. T.; Fillet, M.; Crommen, J.; Jiang, Z. J.; J. Pharm. Bio. Anal. 2017, 140, 348.

18. Wu, M. X.; Wang, J. J.; Zhang, G. J.; Sun S. Q.; Chin. J. Exp. Tradit. Med. Formulae 2010, 16, 54.

19. Michalcová, L.; Glatz, Z.; J. Sep. Sci. 2016, 39, 3631.

20. Qian, C.; Wang, S.; Fu, H.; Turner, RFB.; Li, H.; Chen, D. D. Y.; Electrophoresis 2018, 39, 1786.

21. Zhang, B.; Li, Y. X.; Gao, H. N.; Bian, J.; Bao, J. J.; Electrophoresis 2011, 32, 3589.

22. Liu, X. P.; Du, Y. X.; Eur. J. Med. Chem. 2010, 45, 4043.

23. Bose, S.; Yang, J.; Hage, D. S.; J. Chromatogr. B 1997, 697, 77.

24. Liu, C.; Wei, Y.; Miao, Y.; Zhang, Y.; Pharmazie 2012, 67, 839.

25. Xu, Y.; Hong, T.; Chen, X.; Ji, Y.; Electrophoresis 2017, 38, 1366.

26. Makarska-Bialokoz, M.; Spectrochim. Acta, Part A 2017, 193, 23.

27. Li, G.; Liu, B. S.; Zhang, Q.; Han, R.; Luminescence 2015, 31, 1054. 
28. Cheng, X. X.; Fan, X. Y.; Jiang, F. L.; Liu, Y.; Lei, K. L.; Luminescence 2015, 30, 1026.

29. He, T. X.; Liang, Q. L.; Luo, T. T.; Wang, Y. M.; Luo, G. A.; J. Solution Chem. 2010, 39, 1653

30. Tian, Z.; Zang, F.; Luo, W.; Zhao, Z.; Wang, Y.; Xu, X.; Wang, C.; $J$. Photochem. Photobiol. B 2015, 142, 103.
31. He, T. X.; Liang, Q. L.; Wang, Y. M.; Luo, G. A.; J. Liq. Chromatogr. Relat. Technol. 2010, 33, 548.

32. Li, G.; Liu, B. S.; Zhang, Q.; Han, R.; Luminescence 2015, 31, 1054.

33. Tayyab, S.; Izzudin, M. M.; Kabir, M. Z.; Feroz, S. R.; Tee, W. V.; J. Photochem. Photobiol. B 2016, 162, 386. 